\title{
Atitude fenomenológica e atitude psicoterápica
}

\section{Phenomenological attitude and psychotherapeutic attitude}

\author{
I hana F. de A. Leal* \\ Graduação em Psicologia pela Universidade Federal Fluminense - UFF, Niterói, RJ, \\ Brasil
}

J oana L. Sant' Anna**

Graduação em Psicologia pela Universidade Federal Fluminense - UFF, Niterói, RJ, Brasil

\section{J oelma da C. Bueno***}

Graduação em Psicologia pela Universidade Federal Fluminense - UFF, Niterói, RJ, Brasil

\section{Letícia R. de A. Souza****}

Graduação em Psicologia pela Universidade Federal Fluminense - UFF, Niterói, RJ, Brasil

Roberto N. de Sá

Professor Associado da Universidade Federal Fluminense - UFF, Niterói, RJ, Brasil

\section{Introdução}

Este trabalho tem como objetivo investigar a relação entre atitude psicoterápica e atitude fenomenológica, utilizando-se o método de Pierre Vermersch de entrevistas de explicitação. As entrevistas foram realizadas com psicólogos clínicos de diferentes abordagens teóricas. O estudo visa contribuir para as práticas psicológicas clínicas, seja nos espaços de atuação ou de formação, por meio de uma elaboração temática da atitude de atenção clínica a partir de um referencial fenomenológico. As entrevistas de explicitação da experiência clínica dos psicoterapeutas colaboradores tiveram como foco principal investigar a existência de diferenças entre a atenção no momento do atendimento clínico e a atenção no cotidiano. As diferenças explicitadas foram, posteriormente, correlacionadas com as atitudes natural e fenomenológica conforme diferenciadas por Husserl.

\section{Metodologia}

Esta pesquisa teve como principal fonte de dados o material colhido através de oito entrevistas qualitativas realizadas com psicoterapeutas de diferentes abordagens teóricas e tempos de 
experiência no exercício da clínica. As entrevistas foram feitas seguindo a metodologia fenomenológica de Pierre Vermersch (1994), denominada como "entrevista de explicitação".

Neste modelo de entrevista, o entrevistador participa ativamente de uma introspecção guiada, mas não dirigida, convidando os participantes à prática da atitude fenomenológica e à explicitação de sua experiência. As intervenções do entrevistador buscam facilitar o entrevistado a suspender seus juízos e representações prévias para deixar vir uma "fala encarnada", que exprima a própria experiência. O entrevistador quer fazer com que a experiência fale através do entrevistado e não que o entrevistado fale sobre a experiência. A idéia é que o entrevistado não use conceitos já formados, julgamentos ou opiniões. No "domínio conceitual" (VERMERSCH, 1994, p. 35), o entrevistado se afasta da experiência encaixando-a em categorias. No "domínio descritivo", almejado neste tipo de entrevista, há uma circularidade entre a fala e a própria experiência. O entrevistado fala da experiência de modo descontínuo, alternando entre o relato de sua experiência e suas reflexões sobre ela, que podem ratificar ou retificar o que foi anteriormente dito. Busca-se, portanto, obter uma descrição menos automática e mais reflexiva.

A principal questão proposta na entrevista é se o entrevistado consegue perceber alguma diferença entre seu modo de atenção no exercício da prática clínica e o seu modo de atenção na maioria das atividades cotidianas. O objetivo inicial é testar nossa hipótese de que na atenção psicoterápica há um desvio para o "vivido", para o plano de sentido das narrativas, diferentemente da tendência cotidiana de se deixar absorver pela suposta objetividade já constituída daquilo que se dá à experiência.

Quando os entrevistados afirmam perceber esta diferença, seguimos então pedindo para que a explicitem mais detalhadamente, buscando observar de forma imediata a própria experiência de atenção clínica. Interessa-nos saber como surge essa atenção diferenciada, se há estratégias, voluntárias ou não, para estabilizá-la e que tipo de dificuldades ou facilitadores podem ser identificados no exame da experiência.

\section{Resultados e Discussão}

Independentemente de suas abordagens, os profissionais mostraram forte interesse sobre nossa indagação, sugerindo que o tema da atenção é uma preocupação muito presente em suas práticas. 0 pedido de que as respostas fossem dadas baseadas em suas experiências - e não em teorias aprendidas - foi quase sempre considerado, apesar do variado grau de dificuldade dos entrevistados para fazer essa diferenciação. Mesmo aqueles entrevistados cujas abordagens teóricas não tratavam diretamente o tema da atenção, depararam-se, na observação da experiência, com esta questão, 
percebendo seu atravessamento como algo relevante no processo psicoterapêutico. Todos os entrevistados foram capazes de perceber diferenças significativas em seu modo de atenção clínica e na maioria dos relatos foi possível identificar pontos de aproximação com a atitude de suspensão fenomenológica. Quanto às estratégias para a emergência e a estabilização de uma atenção diferenciada, os entrevistados trouxeram uma gama bastante variada de aspectos relevantes. Apesar de muitos temas se repetirem, permitindo agrupamentos significativos, o modo de suscitar e lidar com a atenção no exercício da clínica é quase que individual e construído a partir da experiência. Este resultado sugere que apesar de ser possível falar em uma certa convergência da atitude clínica, as teorias e técnicas presentes na formação profissional são apropriadas de modo bastante diversificado, sendo talhadas e modificadas conforme a experiência individual.

A análise das entrevistas aponta para a necessidade de um esforço para manter a atenção nos atendimentos, que aparece de forma mais intensa no início do exercício clínico, e se torna mais estável com a prática. Isto é, uma maior segurança e menor ansiedade nos atendimentos influenciam a atenção. Apesar de ser necessário para a entrada no modo de atenção próprio da clínica um direcionamento específico da atenção - muitas vezes chamado de 'esforço' -, em muitas entrevistas encontramos falas situando essa atenção como algo sereno, tranquilo, caracterizada pelo deixar-vir, pela espera.

O tempo de experiência clínica é visto tanto como um agente facilitador da entrada em um modo diferenciado de atenção, como também algo que pode provocar a automatização da atitude clínica. Por isso, é necessária a constante renovação da atenção psicoterapêutica.

A atenção durante a clínica também é relacionada, pelos entrevistados, ao vínculo terapêutico estabelecido com o cliente. I sto, na medida em que, segundo a explicitação de alguns entrevistados, a atenção clínica se mantém mais constante quando o vínculo terapêutico é forte. Ou seja, é ressaltada a importância do vínculo com o outro, vivida como forma de facilitação para a presença atenta durante o encontro clínico.

Alguns entrevistados explicitaram um redirecionamento da atenção, uma mudança de focalização no resultado ou intervenção adequada, para uma focalização na fala do cliente. A possibilidade deste redirecionamento foi associada à percepção das próprias ansiedades e expectativas do psicoterapeuta.

As diferença entre os modos de atenção no cotidiano e na clínica, explicitadas pelos colaboradores, indicam que a atenção específica da clínica não é algo espontâneo, mas que é desenvolvida a partir da prática. Ainda assim, na maioria dos casos, os entrevistados não tinham uma apropriação temática sobre "como" essa atenção é 
estabelecida. Esse aspecto do estudo merece um desdobramento posterior mais sistemático em virtude da sua relevância para a formação clínica.

\section{Conclusão}

$\mathrm{Na}$ análise das entrevistas, pudemos observar características relevantes da atenção clínica, que foram diferenciadas da atenção cotidiana pelos entrevistados. Dentre tais características, destacamse: a presença de uma atitude mais contemplativa, de espera, em oposição a uma ansiedade investigativa mais intervencionista; um olhar mais ampliado, mais voltado para o contexto relacional do que para seus elementos particulares; a inclusão dos estados subjetivos do psicoterapeuta em seu campo de atenção; uma atenção mais direcionada para a experiência dos clientes do que para a suposta objetividade do conteúdo narrado. Estas características da atenção na clínica, evidenciadas no estudo, sugerem a pertinência de uma aproximação entre a "atitude psicoterápica" e a "atitude fenomenológica" descrita por Edmund Husserl (1986; 1992) e apropriada em modulações diferenciadas pelo pensamento de Martin Heidegger (1989; 2000; 2001).

\section{Referências Bibliográficas}

DEPRAZ, N.; VARELA, F.; VERMERSCH, P. A redução à prova da experiência. Arquivos Brasileiros de Psicologia [online]. v. 58 n. 1, 2006.

HEIDEGGER, M. Ser e tempo. Parte I. Petrópolis, RJ: Vozes, 1989.

Serenidade. Lisboa: Instituto Piaget, 2000.

Seminários de Zollikon. Petrópolis, RJ : Vozes, 2001.

HŪSSERL, E. A I déia da Fenomenologia. Lisboa: Edições 70, 1986.

Conferências de Paris. Lisboa: Edições 70, 1992.

VERMERSCH, P. L'entretien d'explicitation. Issy-les-Moulineaux: ESF éditeur, 1994.

\section{Endereço para correspondência}

I hana F. de A. Leal

Instituto de Ciências Humanas e Filosofia - UFF, Praça Leoni Ramos, s/no- Campus do Gragoatá, sala 448, bloco O, $4^{\circ}$ Andar, São Domingos, CEP 24210-350, NiteróiRJ, Brasil

Endereço eletrônico: ihana_leal@yahoo.com.br

J oana L. Sant' Anna

Instituto de Ciências Humanas e Filosofia - UFF, Praça Leoni Ramos, s/no- Campus do Gragoatá, sala 448, bloco O, 4 Andar, São Domingos, CEP 24210-350, NiteróiRJ, Brasil

Endereço eletrônico: jolezan@gmail.com

J oelma da C. Bueno 
Instituto de Ciências Humanas e Filosofia - UFF, Praça Leoni Ramos, s/no- Campus do Gragoatá, sala 448, bloco O, 4 Andar, São Domingos, CEP 24210-350, NiteróiRJ, Brasil

Endereço eletrônico: bueno_j@hotmail.com

Letícia R. de A. Souza

Instituto de Ciências Humanas e Filosofia - UFF, Praça Leoni Ramos, s/no- Campus do Gragoatá, sala 448, bloco O, 4 Andar, São Domingos, CEP 24210-350, NiteróiRJ, Brasil

Endereço eletrônico: le_reis_@hotmail.com

Roberto N. de Sá

Instituto de Ciências Humanas e Filosofia - UFF, Praça Leoni Ramos, s/no- Campus do Gragoatá, sala 448, bloco O, 4 Andar, São Domingos, CEP 24210-350, NiteróiRJ , Brasil

Endereço eletrônico: roberto_novaes@terra.com.br

\section{Notas}

*Bolsista IC-PIBIC/CNPq UFF/2010

$* *$ Bolsista IC-FAPERJ/2009

$* * *$ Bolsista IC-PIBIC/CNPq UFF/2009

$* * * *$ Bolsista IC-FAPERJ / 2010

***** Pesquisador, vinculado ao Programa de Pós-Graduação em Psicologia na área de concentração Estudos da Subjetividade, Universidade Federal Fluminense - UFF. 